Original Research Article

\title{
Antibiotic susceptibility pattern of extended spectrum $\beta$-lactamase ESBL producing gram negative bacilli in a tertiary care teaching hospital, Bareilly, India
}

\author{
Anju Saxena', Sujata Singh ${ }^{2 *}$, Rahul Goyal ${ }^{3}$, Sumit Saxena $^{4}$
}

\begin{abstract}
${ }^{1}$ Department of Pharmacology, T.S. Misra Medical College and Hospital, Amausi, Lucknow, Uttar Pradesh, India

${ }^{2}$ Department of Pharmacology, ${ }^{3}$ Department of Microbiology, Shri Ram Murti Smarak Institute of Medical Sciences, Bareilly, Uttar Pradesh, India ${ }^{4}$ Department of Community Medicine, T.S. Misra Medical College and Hospital, Amausi, Lucknow, Uttar Pradesh, India
\end{abstract}

Received: 19 November 2018 Accepted: 28 December 2018

\section{*Correspondence to: \\ Dr. Sujata Singh, \\ Email: sujatasinghdr@ rediffmail.com}

Copyright: (C) the author(s), publisher and licensee Medip Academy. This is an openaccess article distributed under the terms of the Creative Commons Attribution NonCommercial License, which permits unrestricted noncommercial use, distribution, and reproduction in any medium, provided the original work is properly cited.

\begin{abstract}
Background: The increasing prevalence of infections caused by antibioticresistant bacteria makes empirical treatment of these infections difficult. Resistance to a wide variety of common antimicrobials has made the proliferation of extended spectrum $\beta$-lactamase (ESBL) producing strains a serious global health concern that has complicated treatment strategies and is very alarming. This study was undertaken to identify ESBL production in various gram negative bacilli isolated and to further study the antibiogram of ESBL producers and their contribution towards anti-microbial resistance.

Methods: A total of 2008 samples were taken and studied for positive bacterial growth. Presence of ESBL positivity was detected using Kirby-Bauer sensitivity testing method and their antibiogram was studied. Data was analysed using IBM SPSS version 20. Chi-square test was applied wherever applicable to check the significant difference among the different groups. $p$ value of $\leq 0.05$ was considered to be significant.

Results: A total of 2008 samples were studied. Out of which 655 gave positive bacterial growth and amongst these 312 were ESBL producers. Resistance to multiple classes of antibiotics was observed among ESBL producers and mostly imipenem, colistin and polymyxin B were the antibiotics which were sensitive to most of the strains.

Conclusions: The frequency of ESBL producing strains among clinical isolates has been steadily increasing. Advance drug resistance surveillance and development of newer antibiotics is necessary to guide the appropriate and judicious antibiotic use.
\end{abstract}

Keywords: Antimicrobial resistance, Colistin, ESBL, Imipenem

\section{INTRODUCTION}

$\beta$-Lactam antimicrobial agents represent the most common treatment for bacterial infections and continue to be the leading cause of resistance to $\beta$-lactam antibiotics among Gram-negative bacteria worldwide and thus emergence of $\beta$-lactamase producers have become a matter of serious concern. Extended-spectrum beta lactamases (ESBLs) are enzymes that confer resistance to all $\beta$ - lactam antibiotics except cephamycins and carbapenems and now some ESBLs are even resistant to carbapenems. Treatment of these multiple drug-resistant organisms is a therapeutic challenge. ESBLs are able to hydrolyze $3^{\text {rd }}$ and $4^{\text {th }}$ generation cephalosporins and monobactams. ESBL producing strains are inhibited by $\beta$-lactamase inhibitors (clavulanic acid, sulbactam and tazobactam). ${ }^{1,2}$ ESBL 
isolates were first detected in Western Europe in the mid1980s. Since then, their incidence has been increasing steadily. In recent surveys, a significant increase in the ESBL rate was reported from all parts of the world. ${ }^{3-10}$ Klebsiella pneumoniae and Escherichia coli remain the major ESBL-producing organisms isolated worldwide, which are recommended to be routinely tested for and reported by the Clinical and Laboratory Standards Institute. ${ }^{11,12}$ In addition, bacteria harbouring ESBLs may also acquire and most often exhibit additional resistances to other antimicrobial classes such as the quinolones, tetracyclines, cotrimoxazole, trimethoprim, and aminoglycosides, which further limits therapeutic options and thus pose a therapeutic crisis. ${ }^{13-16}$ Prevalence of ESBLs varies from an institute to another. However, there is paucity of scientific information available on antibiotic profile with rate of ESBL production. Keeping in view the above facts, the present study was undertaken to find the antimicrobial susceptibility pattern of ESBL producers and contribution of ESBL towards anti-microbial resistance.

\section{METHODS}

The design of this study was cross sectional study and the study conducted at the Department of Pharmacology in collaboration with Department of Microbiology, Shri Ram Murti Smarak Institute of Medical Sciences, Bhojipura, Bareilly. The study period was April 2013 to March 2014

Clinical isolates of various gram positive and gram negative organisms, from sputum, endotracheal tip, tracheal aspirate, urine, pus swab, pus aspirate, bronchial wash, catheter tip, blood, pleural fluid, peritoneal fluid, pericardial fluid, ascitic fluid, sample from shunt tube, corneal swab, intracervical swab, wound tissue, CSF and drainage tip from the inpatients and outpatients of Obstetrics and Gynaecology, Surgery, Medicine, Orthopaedics, Ophthalmology, Paediatrics, Casualty, ENT, ICU wards were taken from Microbiology records.

The study was conducted in compliance with the protocol and the Institutional Ethics Research Committee (IERC).

Data was collected from records of Bacteriology Laboratory of Microbiology Department. All the collected data was grouped in two categories i.e. indoor samples and outdoor samples. Further isolates were screened for ESBL production.

The sensitivity and resistance pattern of ESBL producing bacteria was analysed by Kirby-Bauer sensitivity testing method and was compared between the two groups. Muller Hinton Agar (MHA) media was used. The antibiotic sensitivity was designated ' $\mathrm{S}$ ' if the drug was sensitive while ' $R$ ' was designated to drugs which were resistant. (Note: Intermediate sensitivity was regarded as resistant ' $R$ ' in present study as these drugs based on the susceptibility pattern are usually not utilised for treatment).

\section{Statistical analysis}

The data was analysed using IBM SPSS version 20. Chisquare test was applied wherever applicable to check the significant difference among the different groups. $\mathrm{p}$ value of $\leq 0.05$ was considered to be significant.

\section{RESULTS}

Present cross-sectional study includes a total of 2008 samples from various clinical departments. Of these 2008 samples, $655(32.62 \%)$ specimen gave significant growth of bacteria while rest were either non-pathogenic or sterile (Figure 1).

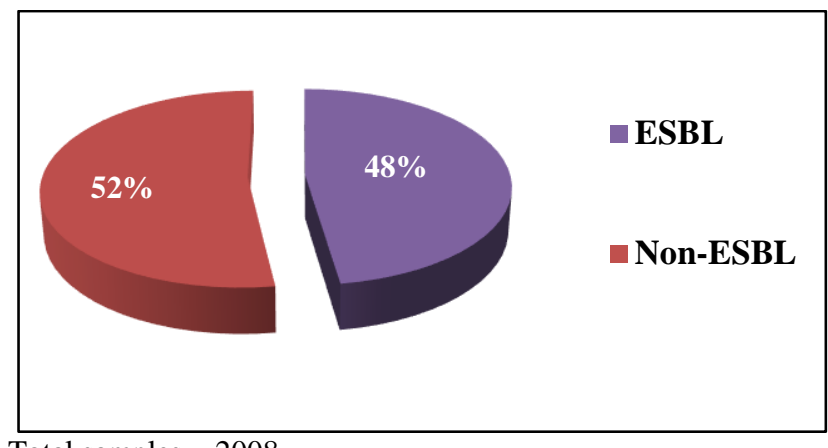

Total samples $=2008$

Figure 1: Total number of samples.

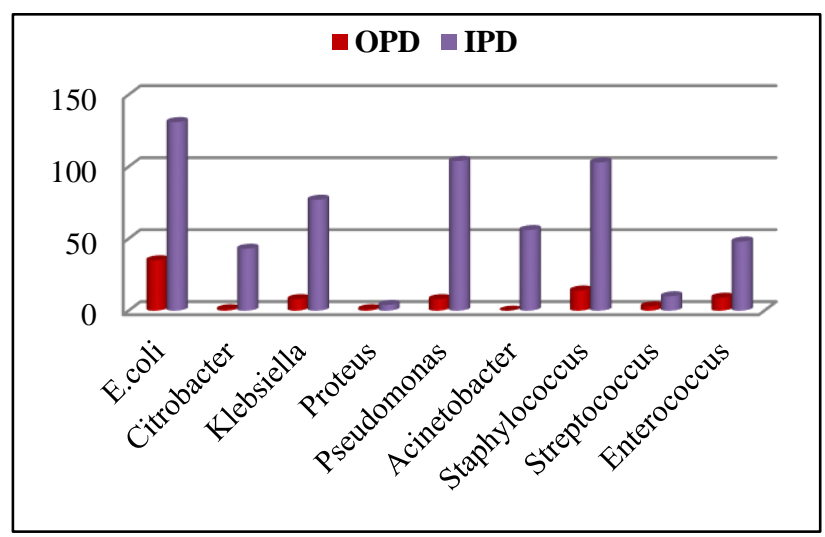

Figure 2: Distribution of organisms in IPD and OPD groups.

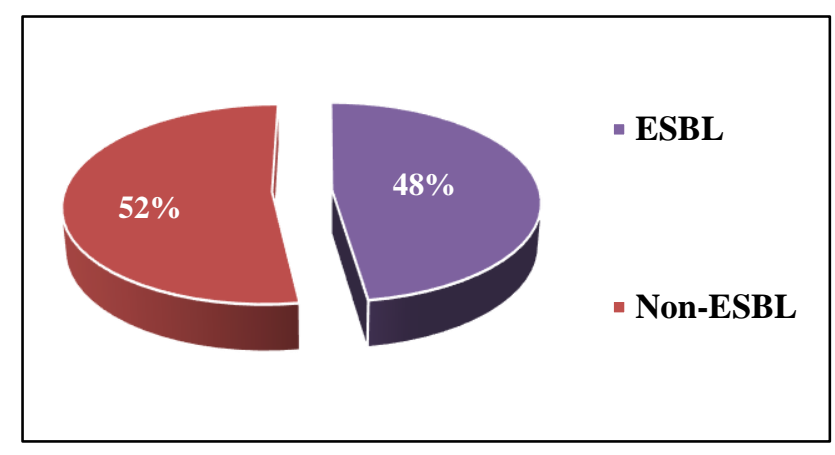

Figure 3: Phenotypically positive ESBL. 
Of the total number of positive isolates $576(87.94 \%)$ were from IPD and $79(12.06 \%)$ specimen were from OPD. Majority of the specimen were infected by gram negative bacteria, E. coli $(25.3 \%)$ (Figure 2). Out of total positive samples, $312(47.63 \%)$ isolates were ESBL producers (Figure 3).

Table 1: Antibiotic sensitivity pattern of ESBL producing enterobacteriaceae.

\begin{tabular}{|llllllllllllll|}
\hline Drugs & $\begin{array}{l}\text { E. coli } \\
\text { IPD }\end{array}$ & $\begin{array}{l}\text { OPD } \\
(\mathbf{n = 1 1 3})\end{array}$ & $\begin{array}{l}\text { p- } \\
\text { value }\end{array}$ & $\begin{array}{l}\text { Klebsiella } \\
\text { IPD } \\
(\mathbf{n = 5 9})\end{array}$ & $\begin{array}{l}\text { OPD } \\
(\mathbf{n = 2})\end{array}$ & p-value & $\begin{array}{l}\text { Proteus } \\
\text { IPD } \\
(\mathbf{n = 2})\end{array}$ & $\begin{array}{l}\text { OPD } \\
(\mathbf{n = 0})\end{array}$ & $\begin{array}{l}\text { p- } \\
\text { value }\end{array}$ & $\begin{array}{l}\text { Citrobacter } \\
\text { IPD } \\
(\mathbf{n = 3 3})\end{array}$ & $\begin{array}{l}\text { OPD } \\
(\mathbf{n = 0})\end{array}$ & $\begin{array}{l}\text { p- } \\
\text { value }\end{array}$ \\
\hline Cip & 1.77 & 5.26 & $>0.05$ & 16.95 & 1 & $>0.05$ & 0 & 0 & N.A. & 27.27 & 0 & N.A. \\
\hline Le & 8.85 & 10.52 & $>0.05$ & 20.34 & 2 & $<0.05$ & 0 & 0 & N.A. & 36.36 & 0 & N.A. \\
\hline Of & 1.77 & 5.26 & $>0.05$ & 11.86 & 1 & $>0.05$ & 0 & 0 & N.A. & 27.27 & 0 & N.A. \\
\hline Nx & 0.88 & 5.26 & $>0.05$ & 3.39 & 1 & $<0.05$ & 0 & 0 & N.A. & - & - & \\
\hline AK & 74.34 & 63.16 & $>0.05$ & 35.59 & 1 & $>0.05$ & 0 & 0 & N.A. & 48.48 & 0 & N.A. \\
\hline Gen & 49.56 & 42.1 & $>0.05$ & 23.73 & 1 & $>0.05$ & 0 & 0 & N.A. & 21.21 & 0 & N.A. \\
\hline Tb & 65.49 & 57.89 & $>0.05$ & 32.20 & 1 & $>0.05$ & 0 & 0 & N.A. & 30.23 & 0 & N.A. \\
\hline MRP & 13.27 & 10.53 & $>0.05$ & 27.12 & 1 & $>0.05$ & 1 & 0 & N.A. & 24.24 & 0 & N.A. \\
\hline I & 88.5 & 84.21 & $>0.05$ & 67.8 & 2 & $>0.05$ & 2 & 0 & N.A. & 75.75 & 0 & N.A. \\
\hline Tet & 0 & 26.31 & $>0.05$ & 18.64 & 1 & $>0.05$ & 0 & 0 & N.A. & 21.21 & 0 & N.A. \\
\hline C & 67.26 & 47.36 & $>0.05$ & 30.51 & 2 & $>0.05$ & 2 & 0 & N.A. & 20.3 & 0 & N.A. \\
\hline Cot & 12.39 & 10.53 & $>0.05$ & 3.39 & 0 & $>0.05$ & 0 & 0 & N.A. & 6.06 & 0 & N.A. \\
\hline CFS & 46.02 & 57.89 & $>0.05$ & 32.2 & 2 & $>0.05$ & 1 & 0 & N.A. & 27.27 & 0 & N.A. \\
\hline AMC & 0.88 & 5.26 & $>0.05$ & 3.39 & 0 & $>0.05$ & 0 & 0 & N.A. & 6.06 & 0 & N.A. \\
\hline Pit & 52.21 & 57.89 & $>0.05$ & 40.68 & 0 & $<0.05$ & 2 & 0 & N.A. & 42.42 & 0 & N.A. \\
\hline Nit & 28.32 & 52.63 & $<0.05$ & 5.08 & 2 & $<0.001$ & - & & & - & - & \\
\hline Cl & 98.23 & 94.74 & $>0.05$ & 93.22 & 2 & $>0.05$ & - & & & 96.96 & 0 & N.A. \\
\hline PB & 100 & 100 & $>0.05$ & 93.22 & 2 & $>0.05$ & - & & & 100 & 0 & N.A. \\
\hline
\end{tabular}

Table 2: Antibiotic sensitivity pattern of non - fermenting gram negative ESBL isolates.

\begin{tabular}{|lllllll|}
\hline Drugs & $\begin{array}{l}\text { Acinetobacter } \\
\text { IPD }(\mathbf{n}=\mathbf{4 3})\end{array}$ & $\mathbf{O P D}(\mathbf{n}=\mathbf{0})$ & p-value & $\begin{array}{l}\text { Pseudomonas } \\
\text { IPD }(\mathbf{n}=\mathbf{3 6})\end{array}$ & OPD $(\mathbf{n = 5})$ & p-value \\
\hline Cip & 2.32 & 0 & N.A. & 8.33 & 0 & $>0.05$ \\
\hline Le & 23.25 & 0 & N.A. & 8.33 & 0 & $>0.05$ \\
\hline Of & 4.65 & 0 & N.A. & 8.33 & 0 & $>0.05$ \\
\hline AK & 6.97 & 0 & N.A. & 22.22 & 0 & $>0.05$ \\
\hline G & 4.65 & 0 & N.A. & 27.78 & 0 & $>0.05$ \\
\hline Tb & 18.6 & 0 & N.A. & 11.11 & 0 & $>0.05$ \\
\hline Mrp & 23.25 & 0 & N.A. & 5.56 & 0 & $>0.05$ \\
\hline I & 62.79 & 0 & N.A. & 72.22 & 5 & $>0.05$ \\
\hline Tet & 11.63 & 0 & N.A. & - & - & - \\
\hline C & 2.32 & 0 & N.A. & - & - & - \\
\hline Cot & 0 & 0 & N.A. & - & - & - \\
\hline CFS & 6.97 & 0 & N.A. & 11.11 & 0 & $>0.05$ \\
\hline AMC & 0 & N.A. & 0 & 0 & N.A. \\
\hline Pit & 2.32 & 0 & N.A. & 19.44 & 0 & $>0.05$ \\
\hline Cl & 97.67 & 0 & N.A. & 97.22 & 5 & $>0.05$ \\
\hline PB & 100 & 0 & N.A. & 97.22 & 5 & $>0.05$ \\
\hline
\end{tabular}

The frequency of ESBL production was maximum with Escherichia coli (86.26\% IPD, 54.29\% OPD) followed by Acinetobacter (70.78\% IPD), Citrobacter (76.74\% IPD), Klebsiella (76.62\% IPD, 25\% OPD), Proteus (50\% IPD) and Pseudomonas (34.61\% IPD, 62.5\% OPD) (Figure 4). When sensitivity pattern of ESBL positive isolates was done an antibiogram of the isolates was presented in Table 1 and 2 which showed that sensitivity to Aminoglycosides 
for ESBL producing E. coli and Klebsiella ranges between $74 \%$ to $49 \%$ and $36 \%$ to $23 \%$ respectively while imipenem was sensitive to all ESBL positive isolates in a range of $68 \%$ to $88 \%$.

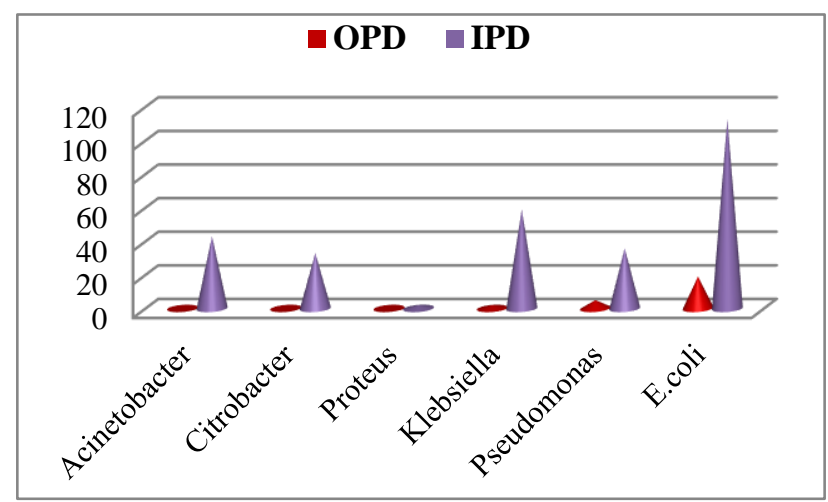

Figure 4: Distribution of ESBL in IPD and OPD.

$\beta$-lactamase inhibitors were mostly sensitive to the ESBL producing enterobateriaceae except non-fermenting gram negative ESBL isolates. Colisitin and polymyxin B, the peptide antibiotics, were the only antibiotics sensitive (almost 100\%) to all ESBL positive isolates. ESBL positive Acinetobater and Pseudomonas were mostly resistant to all antibiotics including fluoroquinolones, aminoglycosides and broad-spectrum antibiotics except Imipenem, colistin and polymyxin B.

\section{DISCUSSION}

ESBLs have become a widespread serious problem. These enzymes are being increasingly expressed by many strains of pathogenic bacteria with a potential for dissemination. Presence of ESBL compromise the activity of widespectrum antibiotics creating major therapeutic difficulties with a significant impact on the outcome of patients. Although the prevalence of ESBL producer varies from country to country, it is more in Asia. ${ }^{17}$ The current study described the antibacterial resistance pattern of ESBL producing organisms including role of ESBL contributing towards antibacterial resistance.

In the present study, $47.63 \%$ of the gram-negative organisms were detected as ESBL producer. This number is less than that previously reported by Dalela et al, and Narayanswamy et al, while in a study conducted in Bangladesh, only $16.07 \%$ were detected as ESBL producer. $^{18-20}$ This variation could be due to the geographical changes.

Out of the total ESBL producers, maximum frequency was observed with Escherichia coli $(79.52 \%)$ in the current study which is in accordance to a study conducted in Chennai which showed ESBL production among 75.5\% Escherichia coli isolates while it was variable in other studies conducted abroad. ${ }^{20-22}$. The reports presented by different authors clearly indicate that the prevalence of
ESBL producing organisms among clinical isolates vary greatly geographically and rapidly changing over time. ${ }^{23,24}$

According to Gales et al, and Mathur et al, Klebsiella was observed to be the second most common ESBL producer but in present study Acinetobacter was found to be the second most common organism producing ESBL with $76.79 \%$ while $71.76 \%$ Klebsiella were ESBL producers showing geographical variation i.e. in this region Acinetobacter is more commonly resistant to $\beta$-lactam antibiotics as compared to Klebsiella. ${ }^{25,16}$ The antibiogram pattern of isolates in the present study shows a higher degree of resistance in ESBL producers. It also revealed that most of the gram negative isolates were largely resistant to fluoroquinolones (73 - 100\%) which might be indicative of higher selective pressure for fluoroquinolones being prescribed which is similar to a study done by Aruna et al, and Jobayer et al. ${ }^{20,27}$ Present study also shows that aminoglycosides are also resistant to Acinetobacter and Pseudomonas which is similar to a study done by Mansury et al. $^{28}$ Sensitivity was maximum with colisitn and polymyxin B followed by imipenem in all ESBL producers in our study which is similar to various other studies done by Solatni et al, Mansury et al, Jobayer et al, Sharma et al. ${ }^{20,22,28,29}$ ESBL strains are usually multi-drug resistant. Because these strains become resistant to available antibiotics, there is a need of emergence of newer antibiotics. Antimicrobial therapy has played an important role in the treatment of human bacterial infections, but the drug resistance that has emerged in the treatment of bacterial infections due to ESBL enzymes degrades all beta lactam antibiotics and thus bacteria become multidrug resistant. $^{30}$

This study was conducted in a limited area and thus may not represent the whole population.

\section{CONCLUSION}

The findings of this study emphasize the need for a continuous surveillance to detect the resistant strains, strict guidelines for the antibiotic therapy and demand the development of newer antibiotics and thus reduce the increasing burden of antibiotic resistance.

\section{ACKNOWLEDGEMENTS}

The authors would like to acknowledge Shri Ram Murti Smarak Institute of Medical sciences, Bareilly for their financial support.

\section{Funding: No funding sources Conflict of interest: None declared \\ Ethical approval: The study was approved by the Institutional Ethics Committee}

\section{REFERENCES}

1. Bradford PA. Extended-spectrum $\beta$-lactamases in the 21st century: characterization, epidemiology, and 
detection of this important resistance threat. Clin Microbiol Rev. 2001 Oct 1;14(4):933-51.

2. Giraud-Morin C, Fosse T. A seven-year survey of Klebsiella pneumoniae producing TEM-24 extendedspectrum $\beta$-lactamase in Nice University Hospital (1994-2000). J Hospital Infection. 2003 May $1 ; 54(1): 25-31$

3. Gupta V. An update on newer beta-lactamases. Indian J Med Res. 2007 Nov 1;126(5):417-27.

4. Livermore DM, Canton R, Gniadkowski M, Nordmann P, Rossolini GM, Arlet G, et al. CTX-M: changing the face of ESBLs in Europe. J Antimicrob Chemotherapy. 2007 Feb 1;59(2):165-74.

5. Stürenburg E, Mack D. Extended-spectrum $\beta$ lactamases: implications for the clinical microbiology laboratory, therapy, and infection control. J Infection. 2003 Nov 1;47(4):273-95.

6. Perez F, Endimiani A, Hujer KM, Bonomo RA. The continuing challenge of ESBLs. Current Opin Pharmacol. 2007 Oct 1;7(5):459-69.

7. Romero ED, Padilla TP, Hernández AH, Grande RP, Vázquez MF, García IG, et al. Prevalence of clinical isolates of Escherichia coli and Klebsiella spp. producing multiple extended-spectrum $\beta$-lactamases. Diagnostic Microbiol Infect Dis. 2007 Dec 1;59(4):433-7.

8. Kuo K, Shen Y, Hwang K. Clinical implications and risk factors of extended-spectrum beta-lactamaseproducing Klebsiella pneumoniae infection in children: a case-control retrospective study in a medical center in southern Taiwan. J Microbiol Immunol Infection. 2007 Jun;40(3):248-54.

9. Hosoglu S, Gundes S, Kolayli F, Karadenizli A, Demirdag K, Gunaydin M, et al. Extended-spectrum beta-lactamases in ceftazidime-resistant Escherichia coli and Klebsiella pneumoniae isolates in Turkish hospitals. Indian J Med Microbiol. 2007 Oct $1 ; 25(4): 346-50$.

10. Messai Y, Iabadene $H$, Benhassine $T$, Alouache $S$, Tazir M, Gautier V, et al. Prevalence and characterization of extended-spectrum $\beta$-lactamases in Klebsiella pneumoniae in Algiers hospitals (Algeria). Patholog Biol. 2008 Jul 1;56(5):319-25.

11. Jacoby GA, Munoz-Price LS. The new $\beta$-lactamases. N Eng J Med. 2005 Jan 27;352(4):380-91.

12. Clinical Laboratory Standards Institute CLSI. Performance standards for antimicrobial susceptibility testing in Proceedings of the 16th International Supplement (M100-S16), National Committee for Clinical Laboratory Standards, Wayne, Pa, USA, 2006.

13. Chopra I, Schofield C, Everett M, O'Neill A, Miller K, Wilcox M, et al. Treatment of health-care-associated infections caused by Gram-negative bacteria: a consensus statement. Lancet Infectious Dis. 2008 Feb $1 ; 8(2): 133-9$.

14. Morosini MI, García-Castillo M, Coque TM, Valverde A, Novais A, Loza E, et al. Antibiotic coresistance in extended-spectrum- $\beta$-lactamase-producing enterobacteriaceae and in vitro activity of tigecycline.
Antimicrob Agents Chemotherapy. 2006 Aug 1;50(8):2695-9.

15. Pitout JD, Laupland KB. Extended-spectrum $\beta$ lactamase-producing Enterobacteriaceae: an emerging public-health concern. Lancet Infectious Dis. 2008 Mar 1;8(3):159-66.

16. Talbot GH. What is in the pipeline for Gram-negative pathogens?. Expert Rev Anti Infect Ther. 2008 Feb;6(1):39-49.

17. Canton R, Novais A, Valverde A, Machado E, Peixe L, Baquero F, Coque TM. Prevalence and spread of extended-spectrum $\quad \beta$-lactamase-producing Enterobacteriaceae in Europe. Clin Microb Infection. 2008 Jan;14:144-53.

18. Narayanaswamy A, Mallika M. Prevalence of extended spectrum beta lactamases in urinary isolates of Escherichia coli in a tertiary care hospital, Chennai, South India. Intl J Med 2011;6 Narayanaswamy A, Mallika M. Prevalence and Susceptibility of extended spectrum beta-lactamases in urinary isolates of Escherichia coli in a Tertiary Care Hospital, ChennaiSouth India. Internet J Medi Update. 2011;6(1):39-43.

19. Dalela G, Gupta S, Jain DK, Mehta P. Antibiotic resistance pattern in uropathogens at a tertiary care hospital at Jhalawar with special reference to ESBL, AmpC $\beta$ - lactamases and MRSA production. J Clin Diagn Res. 2012;6:645-51.

20. Jobayer M, Afroz Z, Nahar SS, Begum A, Begum SA, Shamsuzzaman SM. Antimicrobial susceptibility pattern of extended-spectrum beta-lactamases producing organisms isolated in a Tertiary Care Hospital, Bangladesh. Int J Applied Basic Med Res. 2017 Jul;7(3):189-92.

21. Maya AS, Prabhakar K, Hanna LE, Sarayu YL. Phenotypic and genotypic characterization of extended-spectrum beta-lactamase producing Escherichia coli clinical isolates from semi urban area. J Pharm Res. 2011;4:6-10.

22. Soltani R, Ehsanpoor M, Shokri D. Antimicrobial susceptibility pattern of extended-spectrum $\beta$ lactamase-producing bacteria causing nosocomial urinary tract infections in an Iranian referral teaching hospital. J Res Pharm Pract.2014;3(1):6-11.

23. Krishnakumar S, Rajan RA, Babu MM, Bai VD. Antimicrobial susceptibility pattern of extended spectrum of beta lactamase (ESBL) producing uropathogens from pregnant women. Indian $\mathrm{J}$ Med Healthcare. 2012 Nov 1;1(8):189-92.

24. Babypadmini S, Appalaraju B. Extended spectrumlactamases in urinary isolates of Escherichia coli and Klebsiella pneumoniae-prevalence and susceptibility pattern in a tertiary care hospital. Indian $\mathbf{J}$ Med Microbiol. 2004 Jul 1;22(3):172.

25. Mathur P, Kapil A, Das B, Dhawan B. Prevalence of extended spectrum $\beta$ - lactamase producing Gram negative bacteria in tertiary care hosptital. Indian $\mathbf{J}$ Med Res. 2002;115:153-7.

26. Gales A, Sader H, Jones R, SENTRY participants group (Latin America). Urinary tract infection's trends in the American hospitals: reports from the SENTRY 
Antimicrobial Surveillance programme (1997- 2000). Diagn Microbial Infect Dis 2002;44:289-99.

27. Aruna K, Mobashshera T. Prevalence of extended spectrum beta-lactamase production among uropathogens in South Mumbai and its antibiogram pattern. EXCLI J. 2012 Jul 6;11:363-72.

28. Mansury D, Motamedifar M, Sarvari J, Shirazi B, Khaledi A. Antibiotic susceptibility pattern and identification of extended spectrum $\beta$-lactamases (ESBLs) in clinical isolates of Klebsiella pneumoniae from Shiraz, Iran. Iranian J Microbiol. 2016 Feb;8(1):55.

29. Sharma M, Pathak S, Srivastava P. Prevalence and antibiogram of Extended Spectrum $\beta$-Lactamase
(ESBL) producing Gram negative bacilli and further molecular characterization of ESBL producing Escherichia coli and Klebsiella spp. J Clin Diag Res. 2013 Oct; $7(10): 2173$.

30. Gupta V. An update on newer beta-lactamases. Indian J Med Res. 2007 Nov 1;126(5):417-27.

Cite this article as: Saxena A, Singh S, Goyal R, Saxena S. Antibiotic susceptibility pattern of extended spectrum $\beta$-lactamase ESBL producing gram negative bacilli in a tertiary care teaching hospital, Bareilly, India. Int J Basic Clin Pharmacol 2019;8:228-33. 